\title{
CORRESPONDENCE
}

\section{Why do GPs find management of airways diseases difficult?}

\section{Dear Sirs,}

In my role as a Community Chest Physician, I have found that many general practitioners (GPS) have difficulties in managing patients with diseases of the airways. I believe there are a number of possible reasons for this which warrant debate.

\section{The 'real life' heterogeneity of COPD vs clinical trial populations}

A pre-requisite for a drug trial is a homogenous group of patients. Given that these trials are initiated by the leaders in the discipline, it is therefore understood that the groups identified and tested do form homogenous groups.

However, in clinical practice the COPD population consists of different phenotypes or "many small COPDs", some of which are rare "orphan diseases". ${ }^{1}$ There is considerable overlap between asthma and COPD, particularly in older patients, and fewer than $20 \%$ of older patients have the classical phenotypes of emphysema alone or chronic bronchitis alone. ${ }^{2}$ Furthermore, an estimated $20-40 \%$ of patients with COPD have never smoked, ${ }^{3}$ and almost all large trials of COPD exclude never-smokers. ${ }^{3}$ Given that irreversible airways obstruction ${ }^{4}$ is also a prerequisite for most major trials, it is likely that fewer than 1 in 10 patients with COPD are eligible for inclusion in major clinical trials. Therefore, the exclusion of these patients with COPD may invalidate the evidence base for the management of COPD. In addition, COPD treatments seem to work equally well across all levels of reversibility. ${ }^{5}$

\section{Guideline recommendations}

Guidelines cause problems in at least three ways:

a) As guidelines develop largely as a result of drug trials, and real life patients are not as homogenous as implied by the drug trials, confusion and difficulty can follow.

b) Non-specialist doctors are uncomfortable with guidelines and are less likely to be as knowledgeable as a respiratory trained nurse. This can lead to a de-skilling of the doctor who lets the nurse manage these patients unsupervised.

c) However, a well-trained nurse who follows guideline recommendations may come unstuck with a patient who is incorrectly diagnosed, with a patient who has overlap with another disease (e.g. asthma), and with patients who have multiple (recognised and unrecognised) co-morbidities.

\section{Spirometry}

Despite the recent publication in this journal of Standards for performing spirometry in primary care, ${ }^{6}$ many doctors do not have the time or patience to carry out spirometry. Patients do not enjoy performing spirometry either. ${ }^{7}$ In addition, the instrument is expensive and most general practices will probably only have one machine - and it will most likely be the practice nurse who looks after and uses it.

However, there are inexpensive patient-friendly expiratory flow meters available which will measure $\mathrm{FEV}_{1}$ accurately and can demonstrate airflow obstruction, all carried out in the time it takes to measure the blood pressure. I believe that one of these should be next to the peak flow meter on the doctor's desk, to be used ad lib to identify potential COPD patients. More detailed diagnostic spirometry can then be arranged as necessary. Having immediately available lung function readings will permit more accurate and informed management of these patients.

\section{Training of respiratory nurses}

Looking after patients with COPD is best done with the doctor and suitably trained nurse working as a team. However, because GPs are very busy they are often happy to leave overall management to the practice nurse - who may or may not be a respiratory-trained nurse. Nurse training and team work is crucial. 8

5. The introduction of the UK Quality Outcomes Framework (QOF) One of the major consequences of the UK QOF was the requirement to label patients with airways disease as having either asthma or COPD. The pay structure, further confirmatory diagnostic procedures, and future management including supervision requirements, were then different according to whether the patient had 'asthma' or 'COPD'. This only served to exacerbate the potential diagnostic and management confusion arising from patients with more than one disease or where the diagnosis was uncertain.

\section{The GP}

GPs are problem solvers and are very good at sorting out and dealing with patients presenting with numerous and varied symptoms. This ability is based upon their knowledge of the pathophysiology and treatment of diseases they deal with, as well as their clinical experience.

But GPs are less good at having to follow guidelines. As it happens, experts are also poor at following their own guidelines - which supports the idea that doctor training and guideline implementation are to some extent antithetical...It is as well to remember though, that experts also base their thinking on their knowledge of pathophysiology and their clinical experience. I see no reason therefore why GP education with the aim of producing better understanding of airways disease will not bring about what guidelines have been designed to produce - that is, better patient outcomes.

\section{*Rod Storring ${ }^{a}$ \\ a Consultant Community Respiratory Physician, Barking and Dagenham Community Health Services, Dagenham, Essex, UK \\ *Correspondence: E-mail: r.storring@hotmail.com}

Received 25th February 2011; re-submitted 17th March 2011; accepted 22nd March 2011; online 25th May 2011

Conflicts of interest None.

\section{References}

1. Rennard SI, Vestbo J. The many "small COPDs"; COPD should be an Orphan Disease. Chest 2008;134:623-7. http://dx. doi.org/10.1378/chest.07-3059

2. Gibson PG, Simpson JL. The overlap syndrome of asthma and COPD: what are its features and how important is it? Thorax 2009;64:728-35. http://dx.doi.org/10.1136/ thx.2008.108027

3. Salvi SS, Barnes P. Chronic obstructive pulmonary disease in non-smokers. Lancet 2009;374:733-43. http://dx.doi.org/10.1016/S0140-6736(09)61303-9

4. Beasley R, Weatherall M, Travers J, Shirtcliffe P. Time to define the disorders of the syndrome of COPD. Lancet 2009;374:670-2. http://dx.doi.org/10.1016/S0140-6736(09)61541-5 
5. Soriano J, Mannino D Reversing concepts on COPD irreversibility. Eur Resp J 2008;31:695-6. http://dx.doi.org/10.1183/09031936.00017008

6. Levy ML, Quanjer PH, Booker R, Cooper BG, Holmes S, Small IR. Diagnostic Spirometry in Primary Care. Proposed standards for general practice compliane with American Thoracic Society and European Respiratory Society recommendations. Prim Care Respir J 2009;18(3):130-47. http://dx.doi.org/10.4104/pcrj.2009.00054

7. Cooper BG. Performing good quality spirometry; written for the NATIONAL KNOWLEDGE

\section{Detecting mild COPD is not a waste of resources}

\section{Dear Sirs,}

We thank Professor Enright and Dr White for their linked editorial ${ }^{1}$ on our paper on early diagnosis and early treatment of COPD published in the March issue of the $P C R J .^{2}$ We would like to examine their concerns.

As most patients with COPD are diagnosed late in the disease, we suggested that patients would be advantaged by earlier diagnosis - in terms of lung function severity, symptoms and exacerbations - rather than clinicians simply focusing on those patients who are already diagnosed (as Enright and White suggest).

We disagree that establishing borderline spirometric abnormality following case finding - i.e. identification of symptomatic and clinically impacting disease - is of little value in terms of clinical importance and as a means of enhancing smoking cessation. Evidence from three studies $^{3-5}$ suggesting that COPD diagnosis can be effective in increasing smoking cessation rates has been ignored. ${ }^{1}$ In addition, any opportunity for further discussion with our patients to try to move them one step further in their behaviour change towards smoking cessation is valuable; but this is hard to assess in short-term limited-funding classical randomised trials in potentially biased sub-populations who are willing to undertake such studies. We believe this speaks to the ennui and the frustration of clinicians in providing smoking cessation counselling.

We agree that there is limited proven value in treating GOLD I COPD, but patients need assessment to diagnose more severe disease and to establish asthma differential diagnoses accurately. Asthma misdiagnosis due to the overlap of symptoms is common. ${ }^{6.7}$ Leading questions about the presence of dyspnoea, cough, sputum, wheeze, or frequent respiratory infections in at-risk patients, can assist in identifying those patients requiring spirometry who have probable COPD. .10 $^{-10}$

In addition, patients with undiagnosed GOLD I COPD may already show signs of impaired daily activities (HRQOL)," resulting in deconditioning and an increased risk of social isolation and depression ${ }^{12,13}$ which necessitates intervention. COPD exacerbations occur in patients with milder COPD as well, and can present before COPD is diagnosed ${ }^{14}$ their prevention and appropriate treatment is essential.

Enright and White claim that GOLD II patients are based only on low $\mathrm{FEV}_{1}$ values of $65-80 \%$ predicted, and should be described as either 'probably normal' or "mild restriction with a low FEV 1 and low FVC". ' To our minds the diagnosis of COPD is based first on the $\mathrm{FEV}_{1} / \mathrm{FVC}$ ratio being less than $0.7,{ }^{15}$ with the severity being dependent (as previously mentioned) on the $\mathrm{FEV}_{1}$. Patients with mild restriction should not be labelled as COPD, because they do not have COPD...

Early identification is stated to be of no value because there is no treatment or good biochemical or clinical markers to allow measurement of COPD activity or disease progression. ${ }^{1}$ Whilst we do not yet have any biomarkers predicting disease progression, there are clinical predictors (of disease progression) through increased frequency of exacerbations in those with the clinical phenotype of cough and sputum. ${ }^{16}$

Evidence for short-acting bronchodilator (SABD) use in symptomatic
WEEK for COPD, November 2006

8. Kuethe $M$, Vaessen-Verberne A, Mulder P, Bindels $P$, van Aalderen W. Paediatric asthma outpatient care by asthma nurse, paediatrician or general practitioner: randomised controlled trial with two-year follow-up. Prim Care Respir J 2011;20(1):84-91. http://dx.doi.org/10.4104/pcrj.2011.00003

(c) 2011 Primary Care Respiratory Society UK. All rights reserved.

http://dx.doi.org/10.4104/pcrj.2011.00042

mild COPD is extrapolated from patients with more severe disease, but they continue to be included in all world guidelines. ${ }^{15}$ The widespread use of SABD in these guidelines belies the lack of evidence. The use of long-acting bronchodilators (LABD) in GOLD stage II showed a small 6 $\mathrm{ml}$ improvement in $\mathrm{FEV}_{1}$ annually on treatment with tiotropium, but this was additive to other therapies and not in a population without treatment. ${ }^{17}$ Also, $\mathrm{FEV}_{1}$ improvement does not capture all of the benefit of bronchodilators as evidenced by health status improvement and exacerbation reduction. There is no data to support the use of LABD in GOLD stage I disease.

The suggestion that there is no value in treating milder patients as they are more likely to die of a cardiac problem' seems very utilitarian especially since treating their lung disease may reduce cardiac events which are often associated with COPD exacerbations. In addition, since primary care practitioners take a holistic approach of the entire patient, we realise the importance of linked co-morbidities and the value of treating the whole patient.

In summary, it should be a part of all physicians' care to proactively assess symptomatic patients who are at risk of COPD, thereby hoping to make a diagnosis earlier; this allows earlier institution of both pharmacologic and non-pharmacologic therapies, education, potential interruption of the progressive nature of the illness, prevention of exacerbations, prevention of the development of co-morbidities, and improved patient quality of life. The more good reasons we can give patients to quit smoking, and the more we can relate these to them, the better our chance of assisting our patients in this goal. We feel that the evidence, as well as a common sense approach, clearly supports our position. The IPCRG has created a position statement ${ }^{18}$ on early diagnosis of COPD which provides more information on this topic.

\author{
*Alan Kaplan a , Daryl Freeman ${ }^{\mathrm{b}}$, Jennifer Cleland ${ }^{\mathrm{b}}$, \\ Frank Cerasolic, David Price ${ }^{b}$ \\ a Chair, Family Physician Airways Group of Canada, Richmond \\ Hill, Ontario, Canada \\ b Centre of Academic Primary Care, University of Aberdeen, \\ Aberdeen, UK \\ c Pfizer Inc, New York, NY USA
}

*Correspondence: E-mail: for4kids@gmail.com

Submitted 3rd June 2011; revised 17th June 2011; accepted 19th June 2011; online 17th August 2011

\title{
Conflicts of interest
}

For the full list of authors' conflicts of interest see original article (reference 2 below).

\section{References}

1. Enright P, White P. Detecting mild COPD: don't waste resources. (Editorial) Prim Care Respir J 2011;20(1):6-8. http://dx.doi.org/10.4104/pcrj.2011.00004

2. Price D, Freeman D, Cleland J, Kaplan A, Cerasoli F. Earlier diagnosis and earlier treatment of COPD in primary care. Prim Care Respir J 2011;20(1):15-22. http://dx.doi.org/10.4104/pcrj.2010.00060

3. Górecka D, Bednarek M, Nowiński A, Puścińska E, Goljan-Geremek A, Zieliński J. Diagnosis of airflow limitation combined with smoking cessation advice increases stop smoking rate. Chest 2003;123(6):1916-23. http://dx.doi.org/10.1378/ chest.123.6.191 